\title{
You've Been Followed: How Public Libraries Use Twitter To Engage Their Patrons
}

\author{
Stanislav Orlov, Mount Saint Vincent University, Halifax, Canada \\ Alla Kushniryk, Mount Saint Vincent University, Halifax, Canada
}

\begin{abstract}
The purpose of this study is to examine how public libraries in Canada and the USA use social media to communicate with their patrons. The authors identified Twitter as one of the most popular communication tools, which, however, is often not used efficiently. The researchers collected 38,000 Twitter messages from thirteen public libraries. The data was examined using network analysis based on four proposed dimensions: velocity, reciprocity, centrality and message control. The dimensions of velocity and reciprocity are two major factors in understanding the nature of Twitter messages, while the centrality and message control dimensions are very important in evaluating the impact on the flow of communication and the strength of connections between a library and its patrons. The authors devised a set of recommendations for public libraries to improve their communication strategies in order to increase the number of followers and more actively engage patrons on Twitter.
\end{abstract}

\section{Libraries' Use of Twitter}

Twitter is a popular social network that was launched in 2006 with a mission to "give everyone the power to create and share ideas and information instantly, without barriers". It now has 320 million active users with 1 billion unique monthly visits to sites with embedded Tweets, $80 \%$ of which come from active users on mobile. Twitter has a global reach, with $79 \%$ of accounts outside of the U.S. in over 35 languages. (Twitter, 2016). According to Pew Research Center Survey of around 2,000 U.S. adults nationwide, the number of Twitter users grew up from $8 \%$ in 2010 to $23 \%$ in 2015 (Duggan, 2015).

Organizations around the world are using Twitter to communicate with their stakeholders. Libraries are not an exception. In a study of US public libraries in 38 states, Walt Crawford (2014) found that 953 out of 5,958 libraries (or two thirds of American public libraries) had a Twitter presence. 
He proposed to categorize libraries by size as follows: small libraries are those potentially serving fewer than 10,000 people; medium libraries are those potentially serving 10,000 to 99,999 people; large libraries are those potentially serving 100,000 or more. Crawford found that while only $5.0 \%$ of small libraries had a Twitter account, $23.1 \%$ of medium libraries and $53.1 \%$ of large libraries were present on Twitter. $78.2 \%$ of the largest libraries in the sample, those serving over 500,000 people, had Twitter accounts.

Researchers have mostly focused on examining how libraries are using Twitter (Starr, 2010; Wanucha \& Hofschire, 2013; Burgert, Nann \& Sterling, 2014; Crawford, 2014; Taylor and Francis, 2014) and on evaluation of library activities, influence, and self-representation practices in Twitter (Carscaddon \& Chapman, 2013; Mon \& Lee, 2015). Researchers also studied the impact of social media on librarians and their readiness for this task, as well as the help of library administration in carrying out social networking activities for the library (Gaha $\&$ Hall, 2015). The use of Twitter has been found as mostly beneficial for public libraries, especially due to its low cost and the ability to take library service to users in their preferred spaces (Taylor and Francis, 2014). According to Burkhardt (as cited in Crawford, 2014), the use of Twitter enables libraries to: report library happenings; promote library resources/services; build community; engage users; monitor library related tweets; solicit feedback; and create greater awareness of the library. Additionally, libraries increasingly are using Twitter as a customer service tool (Taylor and Francis, 2014; Appleton \& Tattersall, 2015) and collection development and management tool (Taylor and Francis, 2014).

Despite multiple benefits of Twitter demonstrated through various studies, it can both advantage and disadvantage information users. According to Appleton and Tattersall (2015, p. 23), "it has both the power to alienate and include participants..." as well as to "connect individuals and societies on a huge scale for better or for worse."

Other challenges include considerable time and technological expertise required to maintain an active and visible account, and the pressure for an instant feedback to service queries, because only ever using social media tools to promote library services to patrons is not utilizing the full potential of these tools (Taylor and Francis, 2014; Appleton \& Tattersall, 2015). 


\section{Method}

In our study, we looked at 13 public libraries in Canada and the United States in order to assess their use of social media networks, and particularly Twitter, to communicate with their patrons. We gathered information from a variety of libraries, ranging from smaller provincial and county libraries to the largest libraries in North America. The libraries are located in the eastern, central and western parts of both countries, as well as in the northern and southern parts of the United States. Their annual budgets range from \$2.8 million to almost $\$ 250$ million and the number of cardholders from 24,000 to 3 million (see table 1).

All libraries in the sample had social media presence. We concentrated on their Twitter activities, but all of them also had Facebook pages and 9 libraries had Youtube channels. Eight libraries had Pinterest accounts, 6 Instagram, 4 Tumblr, 3 Flickr. Foursquare and Google+ were used by 2 libraries each, while LinkedIn, Yelp, History Pin, Soundcloud and Googlereads were used by 1 library each.

Table 1 summarizes the publicly available information about the libraries. It was gathered from respective libraries' websites and their official Twitter accounts during January of 2016. We collected 1) all Twitter messages sent by the identified libraries, 2) all Twitter messages that mentioned these libraries, and 3) all replies to libraries' messages from January 12, 2016 until January 26, 2016. The largest public libraries in our sample in terms of the number of cardholders/active users (over 1 million) are New York, Toronto, Los Angeles and Chicago. The next group of libraries (between 300,000 and 500,000) are San Francisco, Calgary, Montreal and Boston. It is followed by the libraries with 24,000 to 175,000 cardholders/active users-Halifax, Knox County (Tennessee), Newfoundland and Labrador, Miami-Dade, Cape Breton.

In terms of budget, the largest libraries (over $\$ 100,000,000$ per year) are New York, Toronto, Los Angeles, Chicago and San Francisco. The next group (from $\$ 42,000,000$ to $\$ 83,000,000$ per year) includes Montreal, Miami-Dade, Calgary and Boston. The smallest group (from $\$ 2,700,000$ to $\$ 23,50,000$ per year) comprises Halifax, Knox County, Newfoundland, Cape Breton. It has to be noted that the dollar amounts obtained from libraries' websites were published when Canadian and US dollars were more or less on par. 
Collection wise, the largest libraries (over 10,000,000 items) are New York, Boston and Toronto. Next group (2,000,000 to 6,500,000 items) consists of Los Angeles, Chicago, Miami-Dade, San Francisco, Calgary and Montreal. The group with the smallest collections includes Halifax, Know County, Newfoundland and Cape Breton (although we could not locate publicly available information regarding the two latter libraries' holdings, it is safe to assume that they hold far less than 1,000,000 items).

At the moment of data collection, in January 2016, New York Public Library had the largest number of followers on Twitter - 1,130,000, while the next largest library, Toronto, had 34 times less followers - 32,900 - despite its number of cardholders $(1,300,000)$ being only 2.4 times smaller than that of New York. At the same time, New York Public Library follows the least amount of other accounts in the sample (108).

In 2010, NYPL won the NonProfit PR Award: Use of Twitter by increasing its online presence and website visits through its @ nypl handle. Among Twitter campaigns ran by the library was a six-week advocacy campaign \#SaveNYPL that it launched to fight a budget cut of $\$ 37$ million - the harshest in its history. It developed a unique decentralized staffing model for coordinating social media effort that included creation of a social media working group to advance the use of Twitter and other social media channels. The group faced a challenge of coordinating over 100 social media accounts across library's branches and divisions. In addition to using HootSuite dashboard, a popular tool for scheduling, monitoring and assigning tweets to staff for follow-up, NYPL enlisted the help of SocialFlow to build the interest and traffic to their blogs via Twitter. SocialFlow, the leading social network optimization platform that "analyzes a customer's real-time conversational data within their social streams and automatically delivers relevant social media content to the right audience at the right time for maximum engagement" (TLC to offer Social Flow to libraries, 2015, p. 9). As a result, @nypl following grew from just under 7,000 to over 90,000 in 2010, while the number of visits to nypl.org coming from Twitter increased by $353.98 \%$ over the previous year (Tinklepaugh, 2010; Brookes, 2011).

Taking into consideration the proportion of Twitter followers to the number of cardholders/active users, New York comes first with 36.22\%. Halifax Public Library was the second best with $10.55 \%$. For the remaining 11 libraries, this proportion on average is $2.77 \%$, 
with Newfoundland and Labrador at $0.56 \%$ of followers to cardholders/active users and Cape

Breton at $7.47 \%$.

\begin{tabular}{|c|c|c|c|c|c|c|c|c|c|c|c|c|c|c|}
\hline & Public Library & is & $\checkmark$ & $<0$ & 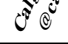 & 50 & \& & 8 \& & 80 & 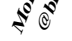 & 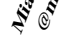 & $0^{\circ}$ ) & & \\
\hline \multirow[t]{3}{*}{ Library Statistics } & Budget/funding (in \$) & $182 \mathrm{mln}$ & $123 \mathrm{mln}$ & $245 \mathrm{mln}$ & $50 \mathrm{mln}$ & $109.4 \mathrm{mln}$ & $23.5 \mathrm{mln}$ & $42 \mathrm{mln}$ & $116 \mathrm{mln}$ & $83.6 \mathrm{mln}$ & $54 \mathrm{mln}$ & $2.8 \mathrm{mln}$ & $10.6 \mathrm{mln}$ & $12.6 \mathrm{mln}$ \\
\hline & Cardholders/active users & $1,300,000$ & $1,200,000$ & $3,119,677$ & 400,000 & 422,704 & 172,520 & 361,639 & $1,016,541$ & 364,680 & 108,484 & 24,200 & 116,157 & \\
\hline & Followers/Cardholders ratio \% & 3 & 1 & 36 & 3 & 3 & 11 & 5 & 2 & 3 & 1 & 7 & 1 & \\
\hline \multirow[t]{3}{*}{ Twitter Statistics } & Following & 1101 & 887 & 108 & 719 & 687 & 5187 & 1931 & 288 & 4770 & 146 & 1569 & 386 & 851 \\
\hline & Followers & 32900 & 13400 & 1130000 & 12300 & 11500 & 18200 & 18300 & 18000 & 9748 & 787 & 1810 & 647 & 3023 \\
\hline & Likes & 1,221 & 13,200 & 864 & 2,489 & 2,903 & 849 & 5,693 & 1,630 & 2,063 & 58 & 553 & 177 & 692 \\
\hline \multirow[t]{10}{*}{ Velocity } & Total number of Twitter messages collected & 2466 & 1702 & 28599 & 1133 & 973 & 998 & 836 & 518 & 101 & 101 & 102 & 54 & 109 \\
\hline & Re-tweets & 1495 & 1130 & 21066 & 760 & 375 & 521 & 426 & 246 & 59 & 34 & 60 & 30 & 65 \\
\hline & Direct tweets & 971 & 572 & 7533 & 373 & 598 & 477 & 410 & 272 & 42 & 67 & 42 & 24 & 44 \\
\hline & Total number of Twitter messages sent by organization & 201 & 202 & 154 & 65 & 125 & 154 & 80 & 54 & 17 & 26 & 37 & 15 & 21 \\
\hline & Number of retweets organization sent & 7 & 37 & 0 & 21 & 21 & 2 & 13 & 30 & 10 & 6 & 15 & 2 & 5 \\
\hline & Total number of unique tweets by organization & 194 & 165 & 154 & 44 & 104 & 152 & 67 & 24 & 7 & 20 & 22 & 13 & 16 \\
\hline & Retweets/tweets ratio organization sent \% & 4 & 22 & 0 & 48 & 20 & 1 & 19 & 125 & 143 & 30 & 68 & 15 & 31 \\
\hline & Total number of organization's tweets being retweeted & 1072 & 740 & 4722 & 204 & 138 & 313 & 235 & 43 & 22 & 2 & 35 & 21 & 35 \\
\hline & Library legitimation of message & 6 & 4 & 31 & 5 & 1 & 2 & 4 & 2 & 3 & 0 & 2 & 2 & 2 \\
\hline & Network legitimation of message $\%$ & 61 & 66 & 74 & 67 & 39 & 52 & 51 & 47 & 58 & 34 & 59 & 56 & 60 \\
\hline \multirow[t]{10}{*}{ Reciprocity } & Who mentions whom network: & & & & & & & & & & & & & \\
\hline & Organization's total degree & 1279 & 756 & 15252 & 503 & 382 & 493 & 432 & 205 & 47 & 33 & 46 & 13 & 65 \\
\hline & In-degree & 1221 & 675 & 15246 & 472 & 342 & 446 & 385 & 178 & 36 & 26 & 31 & 11 & 53 \\
\hline & Out-degree & 58 & 81 & 6 & 31 & 40 & 47 & 37 & 27 & 11 & 7 & 15 & 2 & 12 \\
\hline & In/out ratio & 21 & 8 & 2541 & 15 & 9 & 9 & 10 & 7 & 3 & 4 & 2 & 6 & 4 \\
\hline & Who replies to whom network: & & & & & & & & & & & & & \\
\hline & Total degree & 153 & 66 & 493 & 51 & 30 & 45 & 45 & 21 & 3 & 7 & 6 & 1 & 7 \\
\hline & In-degree & 117 & 60 & 491 & 41 & 28 & 36 & 35 & 17 & 3 & 6 & 5 & 0 & 6 \\
\hline & Out-degree & 36 & 6 & 2 & 10 & 2 & 9 & 10 & 4 & 0 & 1 & 1 & 1 & 1 \\
\hline & In/out ratio & 3 & 10 & 246 & 4 & 14 & 4 & 4 & 4 & & 6 & 5 & 0 & 6 \\
\hline \multirow[t]{7}{*}{ Message control } & Influencer mentions & 62 & 128 & 8437 & 345 & 146 & 50 & 39 & 93 & 2 & 18 & 10 & 22 & 10 \\
\hline & Biggest nod/influencer degree & 42 & 127 & 8352 & 145 & 42 & 35 & 28 & 29 & 15 & 7 & 10 & 10 & 8 \\
\hline & Biggest nod/influencer in-degree & 39 & 125 & 8351 & 142 & 33 & 27 & 27 & 19 & 0 & 5 & 5 & 5 & 8 \\
\hline & Biggest nod/influencer out-degree & 3 & 2 & 1 & 3 & 9 & 8 & 1 & 10 & 15 & 2 & 5 & 5 & 0 \\
\hline & Biggest node/influencer impact \% & 3 & 17 & 55 & 29 & 11 & 7 & 6 & 14 & 32 & 21 & 22 & 77 & 12 \\
\hline & Biggest nod/infuencer activeness & passive & passive & passive & passive & passive & passive & passive & passive & active & passive & mixed & mixed & passive \\
\hline & Is this influencer in the same cluster & no & no & no & no & yes & no & no & yes & no & no & no & yes & no \\
\hline Centrality & Centrality & 0.45 & 0.45 & 0.35 & 0.42 & 0.40 & 0.42 & 0.39 & 0.36 & 0.33 & 0.35 & 0.48 & 0.36 & 0.36 \\
\hline
\end{tabular}


Los Angeles Public Library is unique because it's number of followers $(13,400)$ is almost identical to the number of likes it received $(13,200)$. That is a $98.5 \%$, with the Boston coming a distant second with $31 \%$ and the overall average for the sample being $22 \%$ of likes. Interestingly, New York Public Library only got 864 likes, which is $0.08 \%$ of the number of followers.

\section{Data Collection Procedures and Evaluation Framework}

In this study, we use a multi-dimensional approach to examine how public libraries in Canada and the USA use social media to communicate with their patrons. Four key dimensions were used to describe the type of communication occurring in the library networks. These dimensions are 1) velocity, 2) reciprocity, 3) centrality, and 4) message control.

In our data collection and analysis, we used a specific social media network analyzer called Netlytic. With its help, we collected all tweets posted by libraries in the sample and replies to them, as well as all tweets and retweets that mentioned these libraries from January 12 until January 26, 2016. Netlytic is a Canadian "cloud-based text and social networks analyzer that can automatically summarize large volumes of text and discover social networks from conversations on social media sites such as Twitter, Facebook, Instagram, YouTube, blogs, online forums and chats" (Netlytic.org). This sophisticated tool allows researchers to build and visualize communication networks, making possible discovery and exploration of emerging social connections between individuals within online communities, and providing insights into the nature of the relationships between a library and its patrons.

Velocity. Velocity is a dimension that we use to describe how quickly a Twitter message spreads and resonates among library patrons. This dimension is measured by the network legitimation of messages and the library legitimation of messages.

The network legitimation of a messages for Twitter is determined by the likelihood of a tweet to be retweeted within the network and the speed of this tweet's spread. It is calculated by dividing the total number of retweets (within the network) by the number of all tweets and retweets, and then multiplying by 100 . For example, we collected 2466 tweets that were either sent by Toronto Public Library or mentioned Toronto Public Library, as well as tweets sent in reply to Toronto Public Library's tweets. Out of 2466 tweets, 1495 or $60 \%$ were retweets 
$(1495 / 2466 \times 100=60 \%)$. The highest percentage of retweets in the sample $(74 \%)$ was observed in the New York Public Library network.

The library legitimation of messages was calculated by dividing the total number of a library's tweets, being retweeted by other patrons, by the number of unique tweets sent by this library. For example, New York Public Library sent 154 unique tweets and these tweets were retweeted 4722 times $(4722 / 154=30.66)$. This means that, on average, a message sent by New York Public Library was retweeted approximately 30 times.

Reciprocity. In our study, we define reciprocity as an ability to engage library patrons in twoway communication with a library and to initiate two-way communication among its patrons. We evaluated reciprocity using the following measures:

1. Organizational in/out ratio in name network

2. Organizational in/out ratio in chain network In our analysis, we built two types of networks to analyze two-way communication, labelled 'name' network and 'chain' network (Netlytic.org). A name network (also known as a 'who mentions whom' network) is a communication network built from mining personal names in messages. The chain network (also known as a 'who replies to whom' network) is a communication network built based on participants' posting behavior (Netlytic.org).

For example, for Calgary Public Library the total degree in name ('who mentions whom') network was 503. This number is composed of the in-degree value of 472 (the library's Twitter account was mentioned 472 times in the collected tweets) and the out-degree value of 31 (the library mentioned 31 Twitter users in its messages). As to Calgary Public Library's in/out ratio, it equals 15 , the number derived from dividing 472 by 31 . This means that Calgary Public Library was 15 times more often mentioned by other Twitter users in their messages than it mentioned other Twitter users in its own messages.

In terms of chain ('who replies to whom') network, for Calgary Public Library the total degree was 51(in-degree $=41$, out-degree $=10$ ). The in/out ratio equaled 4.1 , which means that Twitter users replied to the library's tweets four times more often than the library replied to Twitter users' tweets. Ideally, in a chain network, this number should be close to 1, which is the highest level of two-way communication between the library and its patrons and is an indicator of a library's ability to effectively engage in conversations with its patrons and to 
entice its patrons to engage in conversations with each other. Overall, the lowest level of reciprocity was found for the New York Public library.

Centrality. The centrality dimension is used to describe how centralized or decenralized a library's Twitter network is, i.e. whether a library is playing a central role in initiating communication among its patrons. The centrality dimension identifies whether the library's network is overall centralized or decentralized. The Netlytic tool calculates the centrality value automatically. According to Netlytic.org, "when a network has a high centralization value closer to 1 , it suggests there are a few central participants who dominate the flow of information in the network. Networks with a low measurement of centralization, closer to 0 , are considered to be decentralized, where information flows more freely between many participants." Ideally, a balanced centrality is desirable, i.e. high centralization or high decentralization would be considered undesirable. The highest centrality value was found for Cape Breton Public Library, the lowest for New York Public Library.

Message control. The message control dimension is used to describe how well a library controls information flow within its network. To understand the message control dimension, we first need to understand the concept of clusters in network visualization. According to Netlytic.org, "a cluster is a group of densely connected nodes that are more likely to communicate with each other than with nodes outside of the cluster." The "node" in network analysis of Twitter usually represents a Twitter user who is involved in this communication network.

In the analysis of a library's message control, it is very important to identify the following: 1) whether the library's Twitter account is located in the major cluster as the central node of conversation; 2) whether major influencers are located in the same cluster as the library; and 3) what type of influencers the library has. Identifying major influencers in a library's Twitter network is very important in order to analyze the effectiveness of communication with its patrons. The major influencers in networks are identified by the size of the nodes, which is the same as a Twitter user's total degree (as explained above in the discussion on Reciprocity). Major influencers or biggest nodes in the network are not necessarily the top posters in the network. The influencers may be active (actively share/post/retweet or reply to messages), passive (never or seldom share/post/retweet or reply to messages, but are often 
mentioned/replied to by other patrons) or balanced (actively share/post/retweet or reply and are often mentioned/replied to by other patrons). An influencer's impact on a library's network may be classified as high, medium, or low. The library should pay close attention to both high impact active influencers, as well as to high impact passive influencers, even though passive influencers are not active posters and therefore are not easily identifiable with the help of less sophisticated software applications. It is important to identify the location of major influencers within the network, i.e. whether major influencers are in the same cluster with the library or not.

Ten libraries in our sample had low to medium passive influencers in their networks. The New York Public Library is the only one library in our study that had a high impact passive influencer in its network. On January 15, 2016, this influencer, @paul1kirby, a Visiting Professor at the London School of Economics and Non-Executive Director at the Cabinet Office in the UK Government, sent one tweet "Before Google. People would call librarians with stupid questions. Love these 4 from @nypl New York Public Library https://t.co/n17OlnIoay". This tweet went viral and was retweeted 8237 times by January 26, 2016. Paul Kirby is a prolific and popular poster. Since joining Twitter in September 2013, he tweeted and retweeted over 4,700 times. He follows 786 Twitter accounts and has over 8,000 followers. However, by tagging his post with @nypl, he got dozens of times more retweets and likes than he has for an average post. He acknowledged a month later that this was his most popular tweet in 2016 (see Figure 1).

Figure 1:Paul Kirby's most successful tweet in 2016.

Paul Kirby@paul1kirby.Feb 29

ICYMI My most popular tweet in 2016. What people did before Google

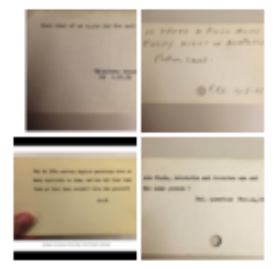

Paul Kirby@paul1kirby

Before Google. People would call librarians with stupid questions. Love these 4 from @nypl New York Public Library

Graph 1 represents the New York Public Library network. This network consists of 28,599 messages posted on Twitter from January12 till January 26, 2016. Out of over 28 thousand messages, 154 were sent by the New York Library, the rest of the messages were retweets, 
replies, and tweets which had mentioned the @ nypl in the message. The NYPL network is relatively decentralised and consists of multiple clusters of conversations. The @ nypl's high impact passive influencer @ paul1kirby is located in the first biggest cluster of the network (see Graph 2). The @ nypl node is located in the second cluster and only one link (or one message) connects@paul1kirby with the@nypl, meaning that @ paul1kirby' cluster 1 constitutes a distinct conversation community from cluster 2 which has @nypl as its central node.

Graph 1: New York Public Library Network

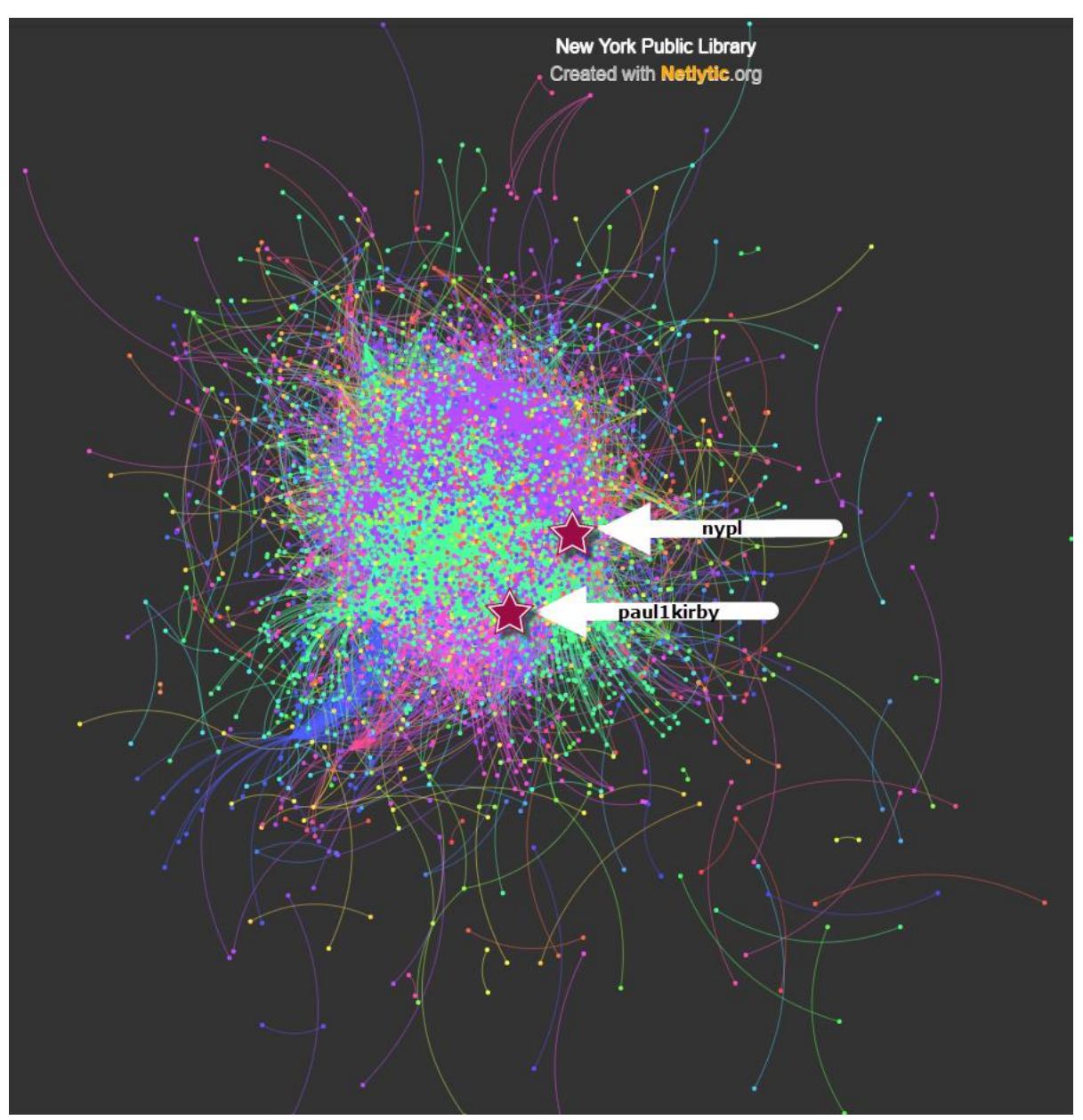

Graph 2: Cluster 1-- Influencer Paul1Kirby

Graph 3: Cluster 2 --New York Library 


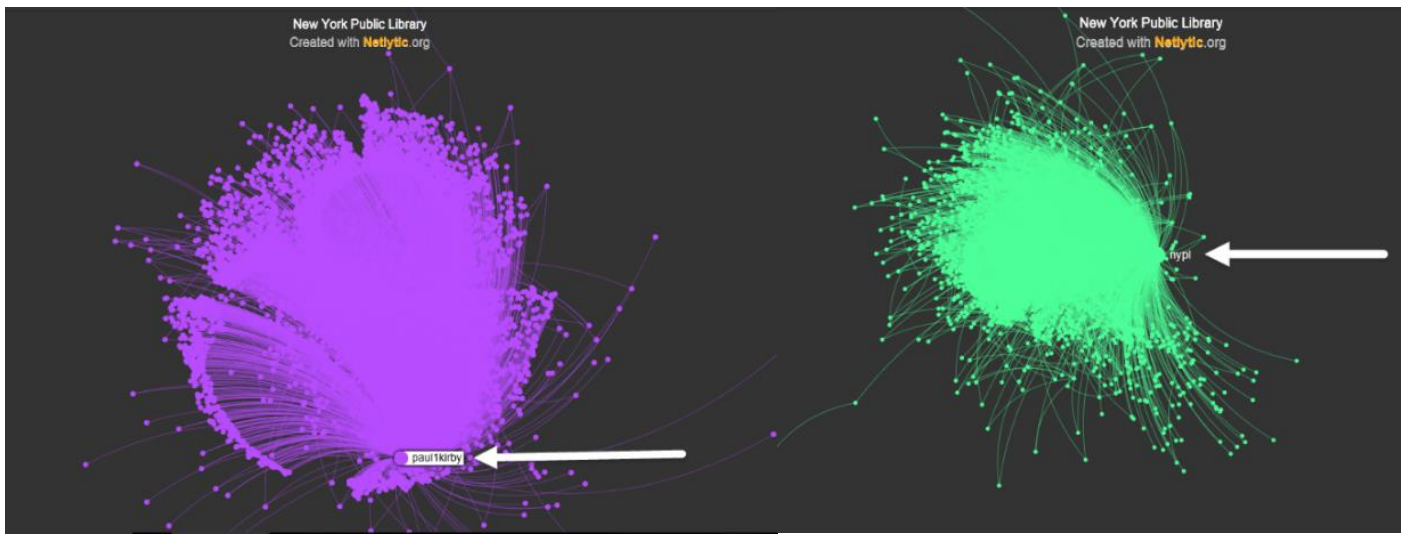

\section{Discussion}

In our study, we evaluated how public libraries in North America use Twitter to engage their patrons. We collected Twitter messages which were later examined using network analyses, based on four proposed dimensions: velocity, reciprocity, centrality and message control. We argue that the dimensions of velocity and reciprocity are two major factors in understanding the nature of Twitter messages, while the centrality and message control dimensions are very important in evaluating the impact on the flow of communication and the strength of connections between a library and its patrons. We found that New York Public Library and Halifax Public Library were the best in our sample of 13 libraries in engaging their patrons on Twitter. However, these libraries have different approaches in how they use Twitter. The New York Public Library outperformed all other libraries on the velocity dimension. On average, a message sent by the New York Public Library is retweeted 31 times, due to the fact that it has 1,130,000 followers. This impressive number of followers makes its network somewhat decentralized, meaning that the library does not dominate the information flow in its network. Despite the fact that New York Public Library is so successful in velocity, i.e. in how quickly a Twitter message spreads and resonates among library patrons, they perform poorly on reciprocity and message control dimensions. Halifax Public Library outperformed New York Public Library on these dimensions, however, they did not do well on velocity. We conclude that replying to patrons' tweets, following other Twitter users, mentioning patrons in messages, retweeting their patrons' tweets, monitoring patrons' conversations will lead to a better patron engagement. 


\section{References}

TLC to offer SocialFlow to libraries. (2015). Advanced Technology/Libraries, 44(2), 9. Retrieved from http://site.ebrary.com

Appleton, L., \& Tattersall, A. (2015). How librarians can harness the power of social media for the benefit of their users. Multimedia Information \& Technology, 41(4), 23-26.

Brookes, A.J. (2011, February 8). New social media case study New York Public Library success with HootSuite [Web log post]. Retrieved from https://blog.hootsuite.com/hootsuite-case-study-new-york-public-library/

Burgert, L., Nann, A., \& Sterling, L. (2014). Ventures in Social Media. Codex, 3(1), 21-44.

Carscaddon, L., \& Chapman, K. (2013). Twitter as a marketing tool for libraries. In Thomsett-Scott, B.C. (Ed.), Marketing with social media: A LITA guide (pp. 147-163). Chicago: American Library Association.

Crawford, W. (2014). Successful social networking in public libraries. Chicago: American Library Association.

Duggan, M. (2015). Mobile messaging and social media 2015. Pew Research Center. Retrieved from http://www.pewinternet.org/files/2015/08/Social-Media-Update-2015FINAL2.pdf

Gaha, U., \& Hall, S. (2015). Sustainable use of social media in libraries. Codex, 3(2), 47-67.

Mon, L., \& Lee, J. (2015). Influence, reciprocity, participation, and visibility: Assessing the social library on Twitter. Canadian Journal of Information \& Library Sciences, 39(3), 279-294.

Starr, J. (2010). California Digital Library in Twitter-Land. Computers in Libraries, 30(7), 23-27.

Taylor and Francis. (2014). Use of social media by the library: Current practices and future opportunities. A white paper from Taylor \& Francis. London: Taylor and Francis. doi:10.6084/m9.figshare.1221673

Tinklepaugh, M. (2010, November 3). Winner: The New York Public Library - Twitter success through a coordinated staffing model. PR News. Retrieved from http://www.prnewsonline.com/awards/nonprofit/2010/11/03/2010-nonprofit-prawardsuse-of-twitter/

Twitter. (2016). About. Retrieved from https://about.twitter.com/company

Wanucha, M., \& Hofschire, L. (2013). US public libraries and the use of web technologies, 2012 (Closer Look Report). Denver, CO: Colorado State Library, Library Research 

Special Issue - December 2016

Service. Retrieved from http://www.lrs.org/wp-content/uploads/2013/11/ WebTech2012_CloserLook.pdf 